\title{
DE CÓMO LA MISMIDAD Y LA OTREDAD REVIVEN LA UTOPÍA. UNA LECTURA DE EL ECO DE LOS PASOS DE JULIETA PINTO
}

\author{
How the values of the Self and Otherness revive the utopia. \\ A reading of El eco de los pasos by Julieta Pinto
}

Verónica Ríos Quesada*

\begin{abstract}
RESUMEN
La crítica literaria sobre El eco de los pasos (1979) de Julieta Pinto se ha enfocado en el desencanto generado por la traición a los ideales que supuestamente dieron pie a la guerra civil costarricense de 1948. En contraposición, este artículo se basa en el análisis de su arquitectura de novela de tesis, provocada desde la inmediatez de la revolución sandinista. La novela promueve la tesis de que la otredad (la sociedad nicaragüense) aspira a los valores de la mismidad (la sociedad costarricense) y dicha familiaridad permite una resignificación del concepto de revolución exenta de tintes izquierdistas. El artículo espera demostrar los mecanismos que permiten la canalización de este mensaje fabricado para una audiencia costarricense. Entre estos se encuentra la construcción de dos planos, uno centrado en el encuentro verosímil entre Carlos Fonseca Amador (basado en el líder sandinista) y Ernesto, el otro, dedicado al 48, narrado por la voz de la memoria reprimida de Ernesto; así como la manipulación del acontecer histórico. En suma, por la solidaridad intrínseca con la causa sandinista, $E l$ eco de los pasos ocupa un lugar particular en la literatura costarricense, generalmente considerada indiferente ante la contemporaneidad de los movimientos revolucionarios centroamericanos.
\end{abstract}

Palabras clave: El eco de los pasos, literatura costarricense, crítica literaria, Julieta Pinto, Carlos Fonseca Amador.

\section{ABSTRACT}

Literary critics when reading the novel El eco de los pasos (1979) by Costa Rican author Julieta Pinto have focused on the betrayal of the ideals that supposedly inspired the Costa Rican Civil War of 1948. Instead, this article analyzes its architecture as an ideological novel, written in the midst of the Nicaraguan Sandinista revolution. The novel establishes the thesis that the Otherness (the Nicaraguan society) aspires to the values of the Self (those of Costa Rican society). This allows a re-conceptualization of the term "revolution" exempt of leftist connotations. This article demonstrates the mechanisms put in place to channel this Costa Rica oriented message. Among those, the construction of two plot lines: one dedicated to a plausible interaction between Carlos Fonseca Amador (based on the Sandinista leader) and Ernesto, a veteran of the Civil War; the other, to the 48 conflict narrated by the repressed memory voice of Ernesto, as well as a tailored manipulation of historical events. In short, the deep- rooted solidarity with the Sandinista cause puts El eco de los pasos in a particular place in Costa Rican literature, generally considered indifferent to the contemporaneity of the Central American revolutionary movements.

Key Words: El eco de los pasos, Costa Rican literature, literary criticism, Julieta Pinto, Carlos Fonseca Amador.

Universidad de Costa Rica. Profesora, Escuela de Filología, Lingüística y Literatura. Costa Rica.

Correo electrónico: veroriosq@gmail.com

Recepción:2/3/16. Aceptación:28/3/16. 
La historiografía literaria costarricense se refiere a las novelas El eco de los pasos de Julieta Pinto (1979), Final de calle de Quince Duncan (1979) y Los vencidos de Gerardo César Hurtado (1977), como la trilogía del desencanto, pues las tres comparten el mostrar la Guerra Civil de 1948 a la luz severa de su contemporaneidad, es decir, de la crisis del Estado benefactor costarricense de la década de 1970. Si bien El eco de los pasos ahonda en la crítica del levantamiento y sus logros, a diferencia de Final de calle y Los vencidos, destaca por establecer un contrapunto internacional a la hora de representar la guerra civil. Este contraste se presenta en la obra a través del desarrollo de dos planos temporales inspirados en eventos históricos: el pasado relacionado con los eventos del 48 y el presente ligado al encarcelamiento del líder sandinista Carlos Fonseca Amador en Costa Rica, en 1969.

En síntesis, como señala Jacinto Brenes, la novela "asume una práctica social de rechazo y distanciamiento ante la clase dirigente socialdemócrata de la década del 70 y de aceptación y acercamiento a los ideales éticos revolucionarios del sandinismo" (2003, p. 59). Sin embargo, ese distanciarse y acercarse simultáneos supone la paradójica puesta en escena de 1) la desilusión con respecto a un movimiento revolucionario triunfador, pues así se caracteriza en la novela al llamado "figuerismo", y 2) la fe ante otro que está en vías de consolidación, es decir, el sandinismo.

Ante esta oscilación, la crítica se ha enfocado en el primer punto, al afirmar el desencanto generado por la traición a los ideales que supuestamente dieron pie a la guerra civil costarricense ${ }^{1}$. Se ha dejado de lado el análisis del componente sandinista, la relación entre los planos y, en suma, su arquitectura como novela de tesis ${ }^{2}$, provocada desde la inmediatez de la revolución sandinista. Tomar en cuenta estos puntos a la hora de releer El eco de los pasos, revela cómo esta novela de tesis se basa en la articulación de un aire de familia con el fin de abrir el espacio para la solidaridad (costarricense) con el otro (nicaragüense): la otredad (la sociedad nicaragüense) aspira a los valores de la mismidad (la sociedad costarricense).

Como desarrollo a continuación, la claridad del mensaje cargado de valores universales depende, en primer lugar, de los mecanismos de construcción de la novela. Entre otros, se basa en la modelación de los personajes centrales Carlos Fonseca y Ernesto, en la verosimilitud de su encuentro, en el manejo de las instancias narrativas y en el contrapunteo de los planos temporales. Una vez puesta en marcha la arquitectura, se articula y se reitera la tesis de que tanto la sociedad costarricense como la nicaragüense deben aspirar a una revolución sin fin y, así, honrar el sacrificio y el dolor de los caídos en la lucha. Además, este destino común implica la solidaridad entre los pueblos. Ahora bien, como se aborda en la tercera sección, no sería posible la canalización del mensaje sin manipulaciones del entorno histórico.

\section{El andamiaje de la novela de tesis}

En primer lugar es importante cuestionarse cómo se establece la verosimilitud del texto y, por tanto, detenernos en la construcción del encuentro entre Carlos Fonseca y Ernesto. Para empezar, es necesario señalar una obviedad y se trata del reconocimiento al líder sandinista nicaragüense Carlos Fonseca Amador por parte de Julieta Pinto, pues desde la dedicatoria ${ }^{3}$, la novela se construye como homenaje a su legado. Al respecto es vital subrayar que Fonseca murió en combate tres años antes del triunfo sandinista, en 1976, y por tanto de la publicación del texto. Como contraparte, se construye el personaje de Ernesto. Al iniciar el levantamiento del 48, era un joven idealista, se podría decir miembro del grupo intelectual que apoyaba al líder José María Figueres Ferrer, que luego de la victoria ocupó cargos de gobierno, pero se alejó del poder para dedicarse a la docencia universitaria.

El encuentro entre los personajes principales es motivado por dos jóvenes no identificados que le piden a Ernesto interceder 
por Carlos, quien se encuentra preso en territorio costarricense. Cuando le mencionan el nombre del guerrillero por primera vez, Ernesto demuestra saber de quién se trata y cuál era el objetivo de su lucha: "Mi deseo de que se derrocara al tirano del norte venía de mucho tiempo atrás. Ahora, este guerrillero se había ido a la montaña con un puñado de hombres para combatirlo" (1984, p. 29). Sin embargo, se muestra escéptico ante la petición de ayuda: "No puedo decirles que el tiempo vivido me ha demostrado que el ideal es un simple sueño, cuando se trata de enclavarlo en la realidad" (p. 30).

Inmediatamente después de este diálogo entre los jóvenes estudiantes y Ernesto, aflora un narrador que resulta confuso, pues se remonta a los eventos del 48 casi desde la omnisciencia, aunque siempre centrado en Ernesto. De esta manera, se construyen dos planos temporales unidos por el personaje de Ernesto y cuyo desarrollo corre en paralelo a través del texto. Dicho en función de las características de la novela de tesis, la estrategia de El eco de los pasos alterna el proceso negativo de aprendizaje del pasado y el que está en proceso. Se diferencia entonces de la estructura más clásica de novelas de tesis con múltiples procesos de aprendizaje, dado que no se presenta la yuxtaposición antitética de aprendizajes negativos. En el modelo tradicional, se cuentan uno o varios procesos negativos para después cerrar con un último positivo -ejemplo de los cuentos en los que de tres hermanos solo el menor tiene éxito(Suleiman, 1993, pp. 84-85).

El primer plano retoma la participación de Ernesto en la lucha figuerista para ahondar en los eventos de la guerra civil. La instancia narradora, situada desde el presente, no solo sabe detalles íntimos de Ernesto, sino que también conoce los pormenores de la revolución. Da la impresión de representar la voz de la memoria reprimida del personaje, imposibilitado de articular su propia experiencia revolucionaria. Por otra parte, en el caso del segundo plano, Ernesto asume la narración del encarcelamiento de Fonseca en Costa Rica a finales de los años 60.
Para el funcionamiento del contrapunteo es vital la buena disposición de Ernesto a escuchar a ese guerrillero nicaragüense, por eso resulta estratégica la recreación de Carlos Fonseca Amador como líder consumado. Desde el segundo capítulo, durante el primer encuentro entre Ernesto y Carlos, se establece la presencia magnética del último:

Todo él irradia una nobleza, una simpatía que se comunica a los presentes y nos hace olvidar la inclemencia de la lluvia, el ambiente nauseabundo de la cárcel, el pensamiento de que aquel hombre necesita ayuda (...) Más que pensar, es un sentir lo que provocan sus palabras (...) Me parece conocerlo desde siempre, como si fuera una parte de mi ser, la parte que aún después de veinticinco años de desilusiones no quiere claudicar, la parte que yo oculto... (pp. 60-61).

Lo conoce porque es la encarnación del ideal que alguna vez persiguió, forma parte de su memoria. De esta manera, gracias a esta conexión idealista, Ernesto valora entonces de una manera diferente a los guerrilleros que combaten en contra de Somoza. Señala el veterano del 48 al hablar con el líder por primera vez:

Todas las noticias que he leído en el periódico sobre un grupo de guerrilleros, que siguiendo los pasos de Sandino, se esconden en las montañas y hacen incursiones a las ciudades para derrocar al tirano, cobran una significación diferente, al saber que éste es el hombre que los dirige. (pp. 61).

Ya en el tercer capítulo, se narra la llegada de Fonseca a Costa Rica y se subraya la urgencia de su liberación, la solidaridad entre combatientes y también la hospitalidad de los costarricenses radicados en las cercanías de la frontera con Nicaragua. Se establece la verosimilitud del encuentro entre Fonseca y Ernesto, puesto que este último asume como misión conseguir el indulto que le permitirá al líder salir de la cárcel, no ser entregado a Somoza y seguir coordinando la lucha armada. De esa manera se establecen las bases de la relación que permite la crítica hacia Costa Rica y la ilusión por el movimiento revolucionario vecino. Los intentos de Ernesto por realizar con éxito su misión alimentan las visitas a Carlos en 
la cárcel y abren el espacio para el diálogo de ambos personajes.

En el fondo, más que un diálogo se establece una relación de alumno-aprendiz similar a la estrategia socrática en la que se inspiran textos didácticos como el Ariel de Rodó ${ }^{4}$, en el sentido, de que gracias a la interacción el alumno aprende. Señala Carlos:

Necesito hablar con Carlos, oír su fe en el futuro del género humano, introducirme en ese mundo de guerrilla donde todavía son reales la solidaridad y el sacrificio (pp. 134).

Al igual como lo señala Roberto González-Echeverría con respecto a Ariel, se crea la ficción de que se trata de un diálogo y no de un discurso pre hecho (2001, pp. 46-48). Sin embargo, a diferencia de este texto clásico de Rodó, no se trata únicamente de un montaje dialógico en la que Carlos use una posición magisterial, pues el tener que abogar por el nicaragüense confronta a Ernesto con su decisión de apartarse de la estructuras de poder. Debe escuchar críticas fuertes al respecto de esa decisión, emitidas por los ex compañeros de lucha que sí permanecieron en las altas esferas. De esa forma, los señalamientos de Fonseca Amador emitidos desde la cárcel, se comprueban en la vida cotidiana con las visitas de Ernesto a los ministerios e incluso en su visita infructuosa al propio Figueres como intento desesperado por conseguir el indulto. En suma, el lector no se encuentra en una situación tan marcadamente subordinada con respecto a los hablantes, gracias al contrapunto de planos y a la participación de aquellos que se erigen como oponentes, es decir, los ex compañeros de Ernesto.

Desde ese punto de vista, el plano del presente, es decir, del encuentro Ernesto-Carlos se modela como proceso de aprendizaje para el costarricense. Siguiendo la descripción hecha por Suleiman con respecto a las novelas ideológicas ${ }^{5}$, Carlos es en términos actanciales el dador y el ayudante de Ernesto en este nuevo proceso de aprendizaje. El nicaragüense ocupa un lugar cada vez más especial, al punto que la admiración del costarricense por él cobra tintes devocionales en la novela. De esta manera, al igual que en el testimonio de Omar Cabezas $L a$ montaña es algo más que un inmensa estepa verde, "la movilización de la terminología religiosa para fines políticos revela la influencia de la religión en la lucha para liberar al país" (Rhoden, 1999, pp. 73).

$\mathrm{Su}$ primer proceso de aprendizaje, es decir, su experiencia como miembro del grupo triunfador del 48, es negativo porque Ernesto no pudo continuar con la labor revolucionaria emprendida y dejó de luchar, pues perdió en el camino a su primer dador/ayudante. Cabe hacer la aclaración de que Figueres no es la figura paternal que lo orienta, sino Herminio, quien muere en el cumplimiento del deber. Así lo hace constar repetidamente la voz de su memoria reprimida en el plano del 48 desde el inicio de la novela: "Era él quien tenía la visión más clara de lo que se debía hacer" (p. 37) y más adelante: "Reconocías la superioridad ante la emergencia y obedecías complacido (p. 95). Al morir Herminio, señala la voz de su memoria: "La muerte de Herminio había anulado tu fe en la revolución" (p. 136).

Esteesunejemplodelacomplementariedad de los planos y de cómo esta refuerza las tesis de la novela, tema de la segunda sección de este artículo. Ahora bien, la novela termina y el lector no sabe si Ernesto realmente pondrá en práctica la lección aprendida. Siguiendo con el prototipo de novela ideológica, el segundo proceso de aprendizaje no concluye porque no hay acción. Carlos invita a Ernesto a que se una a la revolución nicaragüense, pero este último declina la oferta. Al verlo partir señala el renacimiento de esperanza en el futuro, pero no se especifica ningún plan concreto.

Pese a la irresolución, hay un guiño consolador en el desenlace. Por una parte, se narra la salida de Carlos hacia el extranjero. Se marca que la esperanza revolucionaria sandinista se mantiene viva y así concluye el plano del presente. Por otra parte, inmediatamente después se narra la entrada triunfal de los figueristas a la capital para cerrar ese plano temporal. Los dos eventos, es decir, la salida de Carlos y el ingreso glorioso, podrían interpretarse como dos 
inauguraciones, dos promesas de esa máquina llamada utopía (Moylan, 1998, p. 4). De esta manera, cobra sentido el íncipit de la novela: "El fuerte tableteo (...) penetra en los sepulcros para despertar las voces silenciadas que cuentan una historia... La misma historia en el encuentro de dos tiempos..." (p. 27). Se evidencia tanto al inicio como al final de la novela el destino común de Costa Rica y Nicaragua. En consecuencia, las tesis que se revelen a través del texto son válidas para ambas sociedades.

\section{La vigencia de una revolución sin fin inspirada en la costarriqueñidad}

La contraposición de planos da lugar a una oportunidad para que se marquen "esquemas polarizadores de tipo la falsa revolución/la revolución verdadera" (Fernández, 1996, p. 238), propios de la novela de tesis por su propósito didáctico. Sin embargo, en vez de que los revolucionarios sandinistas aprendan de una revolución fallida, de los errores de Ernesto y sus compañeros; sucede lo contrario. Ernesto no es el maestro de Carlos, sino al revés. Este último juzga los hechos de la guerra civil y el desempeño de los triunfadores, a pesar de que no ha ocupado la silla del triunfo. En ese sentido, se plantea que el cortoplacismo de la guerra del 48 significó el fin de su espíritu revolucionario, error que según el personaje Fonseca no se repetirá en el caso del movimiento nicaragüense, y cómo el trauma derivado de toda revolución supone un mal necesario.

Como punto de partida, según el texto, ambos movimientos surgen con apoyo popular. Sin embargo, aunque la narración del 48 de la novela enfatiza en que todos participan en el esfuerzo por desalojar al gobierno corrupto: mujeres, hombres, campesinos, intelectuales, etc.; Fonseca afirma que se traicionó la causa pues solo el sector medio costarricense se benefició con el triunfo (p. 83). La razón por la cual se da el supuesto fracaso del 48 no radica entonces en la antesala del triunfo revolucionario, sino en la continuidad que se le da al proyecto en sí desde la base popular. Esa es la crítica fundamental del personaje Fonseca y esta se fortalece con la intervención de otros personajes en el plano del presente. Rodrigo, uno de los revolucionarios costarricenses convertidos en funcionarios públicos, sostiene sin tapujos que el conformismo del sector campesino es un obstáculo para la mejoría de sus propias condiciones de vida (p. 105). Además, se conectan ambos planos de la novela, pues resuenan las palabras de la esposa de Baudilio, uno de los combatientes campesinos del 48 muertos en combate, quien le dice justo antes de que él parta a la lucha: “ ¿Te va a agradecer alguien lo que hacés? ¿Vas a cambiar el mundo y a salir de pobre?" (p. 58). En suma, la complementariedad de los planos demuestra el divorcio entre quienes están en el poder y los sectores desfavorecidos. Señala Carlos la vocación de lucha y, por tanto, la superioridad -aunque no probada- de los guerrilleros nicaragüenses con respecto a los costarricenses:

Deben de haber sido muy pocos los ilusos como
tú. Y digo ilusos y no idealistas porque el ideal
se crea día a día, se forja con el esfuerzo común
y la determinación conjunta. Es una meta que nos
impide detenernos en el camino o equivocarnos
de ruta. Nuestro grupo luchará por conseguirlo
hasta el último día de nuestras vidas. (pp. 82-83).

Es importante destacar el contraste entre "iluso" e "idealista". Ernesto es acusado, no sin razón, de haber sucumbido a un ideal romántico de la lucha que no implica compromiso real en el tiempo. De hecho, esta recriminación permite entender mejor la construcción del plano del pasado como represión de su experiencia del 48. Se marca una cesura entre su pasado y su presente a través de la estrategia de narración, pues, como se señaló antes, no es él quien narra el plano del 48. En ese sentido, vale la pena recalcar que El eco de los pasos no es una novela histórica o un testimonio narrado desde el punto de vista de Ernesto. Quien le ayuda a conectarse, a redescubrir su identidad, como en las novelas de tesis, es Carlos en primera instancia. En el 
plano del presente, a punto de encontrarse por segunda vez con Carlos señala el ex combatiente:

Quisiera que Carlos no hable más, que no me haga revivir un estado de conciencia, que bastante me ha reprochado el abandono de una trinchera demasiado peligrosa si no había claudicaciones. (p. 84).

Ese estado de conciencia hace referencia a lo señalado en el plano del 48 y que Ernesto no puede articular, es decir, a la evidencia de que no todos los militantes entraron con las mismas intenciones de pureza, de cambio (p. 76), que las familias sufrieron, que las mujeres y los niños corrieron peligro, que a los combatientes les afectó la muerte. Se muestra cómo la violencia se infiltra innegablemente en el tejido social y el dolor causado en todos los participantes. Entre otros se detalla la participación de figuras como Francisco, personaje ficticio a quien se presenta como responsable del histórico asesinato a sangre fría realizado en el tramo del ferrocarril hacia el Atlántico conocido como "El codo del diablo"; deserciones del movimiento ante la violencia infligida al contrario e incluso el peso psicológico de la muerte de los compañeros (p. 137). En otras palabras, se detalla la tragedia que supuso la lucha y cómo, usando las palabras del investigador Manuel A. Solís, se desarrolla la violencia reactiva del conflicto (2007-2008, p. 266).

Ante la falta de introspección de Ernesto y de herramientas para conectar sus experiencias con su presente, destaca nuevamente la figura de Carlos y su discurso. De sus palabras se deduce que la experiencia traumática es inevitable en el contexto de la lucha revolucionaria. Está consciente del sacrificio. Debe trascenderse a través de la continuidad del proyecto revolucionario y la fe en su futuro, pues solo así se legitima como acto de defensa. Para Carlos, el sacrificio del presente se mira como parte vital para alcanzar ese porvenir: "Hemos tenido que pagar con la sangre de nuestros hermanos, pero no será en vano" (p. 109).

Por otra parte, no se trata de que Costa Rica emule a los sandinistas. Fonseca no está insinuando que Ernesto levante una revolución armada en Costa Rica (p. 82). Si bien le indica "la necesidad de politizar revolucionariamente a los intelectuales" (p. 135), en el caso costarricense, la novela plantea una crítica hacia la adoración del objeto en vez de la preocupación por el sujeto, particularmente por el campesino. Fonseca se lo señala a Ernesto: debe trabajar desde adentro. La naturaleza humana no cambia, como indica su excompañero Rodrigo, tiene que estar dispuesto a lidiar con "seres humanos plenos de errores y pasiones" (p. 104).

Curiosamente, esa resignificación del concepto de revolución se rige por una batería de valores que corresponde a la proyección nostálgica de un pasado reconstruido, imaginado de esa costarriqueñidad basada en la paz, la institucionalidad, la armonía, la familia, neutralidad ideológica, el sacrificio, la solidaridad, pero sobre todo en el derecho al sufragio y la defensa del campesinado. El rompimiento de esos valores, por una parte, según el texto, desencadena la revolución del $48 \mathrm{y}$, por otra, nutre el espíritu sandinista. Para muestra, en la siguiente cita, se evidencia cómo la revolución nicaragüense defiende la vida humana ante todo, más cuando se trata de civiles. Afirma Carlos:

El respeto por la vida humana mueve todas nuestras acciones y jamás hemos disparado contra un civil. Hasta dejábamos libres a los guardias nacionales después de quitarles el uniforme y las armas, pero la incidencia en su crueldad, la persecución de nuestros hombres con una saña copiada de su amo, nos ha obligado a no desperdiciar un solo tiro. (p. 61)

Asimismo, como se evidencia en la cita siguiente, el personaje Carlos hace hincapié en la mítica paz de Costa Rica y demuestra estar consciente de la preponderancia de los derechos humanos:

Están [la guardia nacional] acostumbrados al engaño y la mentira en todas las formas imaginables, y eso es nuevo para ustedes. Como también es nuevo y espero que jamás lo aprendan, los métodos de tortura que practican en las cárceles de mi país. Por eso se deja de creer en los derechos humanos y hay que hacer justicia por la propia mano. No es de un momento a otro como se hace uno guerrillero, es una toma de conciencia a través de experiencias muy amargas. (p. 108). 
De esa manera, el texto intenta alejarse de cualquier polémica con respecto a la obvia contradicción que supone el acercamiento entre un líder nicaragüense claramente marxista y un veterano costarricense que combatió la alianza del gobierno con el Partido Comunista. Cuando, en el plano de la guerra del 48, uno de los militantes tilda a Herminio de comunista, este responde:

\begin{abstract}
Estamos claros en que hay que hacer un cambio de estructuras desde nuestro ser costarricense, sin admitir moldes extranjeros que pretendan resolver nuestros problemas. Lástima que el actual gobierno se haya corrompido, pues hubo un momento en que parecía que tomaba camino diferente. La unión entre el gobierno, las clases necesitadas y la iglesia perfilaban un panorama tan interesante, que en pocos años hubiera solucionado los problemas sociales. (p. 45).
\end{abstract}

Se insiste entonces en la necesidad de la "vía tica" y en que el motivo del descontento es la burla al sistema democrático electoral. Cuando, en el contexto del diálogo, uno de los participantes señala: "Eso es lo bueno, que no haya lucha de clases, que una vez que expulsemos al gobierno, vuelva la armonía fraternal" (p. 46), inmediatamente se corrige esa postura conservadora al enfatizar Ernesto la necesidad de que la situación del campesinado finalmente empiece a cambiar. Además, en sus intervenciones, el personaje Carlos Fonseca Amador no usa palabras asociadas con el comunismo ni menciona teóricos marxistas.

Por otra parte, la novela hace énfasis en que los pueblos deben unirse en contra de quienes los agreden. En este caso, se fuerza el texto para que quede muy claro que Somoza y su régimen fue y sigue siendo enemigo común de Costa Rica y de Nicaragua. Incluso se enfatiza la participación violenta e injustificada de somocistas en el bando oficialista, es decir, el "malo" u oponente en términos actanciales, durante la guerra civil del 48. Se narra, por ejemplo, la represión de una manifestación pacífica de mujeres y cómo les disparan a pesar de estar ellas desarmadas. Inmediatamente se aclara que la violencia ejercida es "importada", de extranjeros (p. 34). Señala el narrador: "Era gente acostumbrada a la violencia y trató de imponer sus métodos en un país que nunca había tolerado estos actos" (p. 34). Según el texto, es tal el grado de no violencia de los costarricenses que los propios soldados se excusan de acatar órdenes ante la población civil (p. 50).

Se podría pensar que afirmaciones como la de este militante anónimo: "No hay que preocuparse, son unos grandes pendejos, además éste no es su país" (p. 51), incita a la xenofobia indiscriminada. Sin embargo, el texto se distancia de ella al celebrar simultáneamente la participación de la Legión del Caribe, "una agrupación de hombres, que como nosotros, creen en la libertad" (p. 51) ${ }^{6}$. De esta manera, hace hincapié en la solidaridad de los pueblos y se alude directamente a la necesidad de actuar en el presente del relato. Señala Ernesto, casi al final de la novela:

\footnotetext{
Sumergidos en una democracia que ha ido eliminando hasta la obligación de ayudar a quienes, como nosotros una vez, lo necesitan ahora, prefieren guardar las apariencias de unas relaciones diplomáticas fundamentadas en el engaño y la mentira. (p. 131).
}

Para rematar el llamado a la solidaridad, Ernesto, una vez que se ha reapropiado de su propia experiencia como veterano, cuenta a continuación la historia de Amado, un personaje malogrado basado en el dominicano Amado Soler y miembro de la Legión del Caribe, a quien también se le dedica la novela. De esta manera, evidencia también que los combatientes del 48 rompieron el pacto de solidaridad y, por tanto, permanece una deuda moral con el pueblo nicaragüense:

Había un pacto de solidaridad entre ellos y nosotros, un pacto que nunca se cumplió por las mismas razones por las que ahora no se puede ayudar a Carlos. Ese miedo al tirano, a la locura del tirano que ha sabido explotar tan bien, inhibe al gobierno para tomar decisiones que se debieron haber tomado hace ya muchos años. (p. 132).

En suma, la novela promueve activamente unainterpretación en pos delentendimiento deuna revolución sin fin para ambas sociedades, basada en valores universales, claramente enmarcados 
en los valores estereotípicamente costarricenses, alejados de cualquier tinte socialista o comunista. Basarse en las "comodidades epistemológicas del hogar"7 costarricense, permite entonces la resignificación no amenazante del concepto revolución. Se marca la vitalidad de un movimiento revolucionario permanente, imbuido en un aire de familiaridad para la audiencia costarricense. En otras palabras, se concibe una solidaridad hacia la otredad y sus luchas desde marcadores identitarios ya conocidos: la otredad aspira a mi mismidad, por eso la puedo apoyar.

\section{Manipulaciones para evitar la ambigüedad interpretativa}

Como se desprende implícitamente de las secciones anteriores, la novela realiza importantes simplificaciones para construir este paralelismo revolucionario. En ese sentido, resulta esclarecedora la fecha de publicación: 1979. Es el año del triunfo sandinista y, por tanto, de la caída de la dictadura somocista que ya llevaba casi medio siglo en el poder. Ahora bien, poco importa si se publicó antes o después del 19 de julio, día oficial del derrocamiento, pues si bien su salida al mercado corresponde con el momento primigenio de la utopía, la trama se concentra en el encarcelamiento de Fonseca, acaecido en suelo costarricense entre 1969 y 1970. Significa entonces que se centra en las primeras etapas de la articulación de la lucha en contra de la dictadura somocista; cuando todavía no se había logrado la operación ideológica de cooptar la figura de Sandino para beneficio del movimiento revolucionario en ciernes ${ }^{8}$. De hecho este apellido icónico no aparece mencionado ni siquiera una vez en la novela de Pinto. Hacerlo así facilita el distanciamiento con interpretaciones izquierdistas poco bienvenidas en el ámbito costarricense de la época.

Asimismo, se presenta una referencialidad mínima para recrear tanto la guerra del 48 como el encarcelamiento de Carlos. De esta manera, se acorta la distancia de la audiencia meta ante la revolución sandinista al compararla con el evento costarricense similar más cercano del siglo XX: la guerra civil del 48. Definitivamente en $\mathrm{El}$ eco de los pasos, interesa presentar una imagen particular tanto de los costarricenses como de los nicaragüenses, una que no ahonde en los pormenores de una historia binacional no exenta de fricciones. Por tanto, se aleja del modelo de la novela histórica tradicional.

En cuanto al plano del 48, si bien es cierto se narran enfrentamientos entre bandos, los sabotajes al ferrocarril y a las plantas hidroeléctricas, la capitulación del gobierno, entre otros eventos; se eliminan nombres, apellidos, datos geográficos. Su versión de los hechos dista mucho de plantearse una reconstrucción que al menos intente ser fidedigna, más bien se reduce el conflicto a trazos generales y, como indica Rodrigo Soto, se aborda el tema "desde una perspectiva muy similar a la que terminaría siendo el 'relato oficial' del bando ganador sobre aquellos hechos" (2011, p. 39). De ninguna manera, le interesa incorporar la extensa documentación que ya para 1979 había circulado acerca del 48 desde todo punto de vista: ganadores insatisfechos, ganadores, perdedores, comunistas, etc ${ }^{9}$. Como novela de tesis, necesita marcar claramente los bandos.

Retomando el punto de la participación extranjera en el conflicto civil ya señalado en la sección anterior, es importante marcar la distorsión de la novela, pues en gran medida e independientemente del bando, se trató de nicaragüenses mayoritariamente antisomocistas, específicamente trabajadores bananeros que radicaban en Costa Rica. Incluso, según señala Alemán al escribir sobre la participación nicaragüense en el conflicto, en una de las novelas que conforman el llamado trío del 48, la ya mencionada Final de calle de Quince Duncan, se indica:

Los nicas que andan con nosotros no son los de Somoza. Los que están con Fallas y los linieros son sandinistas (...) Además, esos nicas son de aquí (...) han vivido aquí por mucho tiempo, trabajando en las bananeras. Son trabajadores como uno. (Alemán, 2013, p. 121).

Aunque efectivamente, como lo indica claramente el texto, "el dictador nicaragüense 
Anastasio Somoza García irónicamente asistió a un gobierno apoyado por comunistas para asegurarse de que los aliados de Figueres no se convirtieran en una amenaza para su propio dominio en Nicaragua" (Alemán 113), es incorrecto históricamente centrar el origen absoluto de la violencia reactiva en ese destacamento de la Guardia Nacional de Nicaragua.

En cuanto al encarcelamiento de Fonseca, como acontecimiento histórico, incluso casi cincuenta años después, es difícil encontrar información fidedigna. Hasta la fecha no hay estudios serios al respecto de ese primer canje de prisioneros que logra el movimiento revolucionario. Sin embargo, las omisiones centrales son altamente reveladoras. En primera instancia, la novela no señala las consecuencias del fallido intento de fuga de Fonseca de la cárcel de Alajuela donde estaba confinado. Por una parte se borra la muerte de un policía costarricense durante el enfrentamiento provocado por los sandinistas ansiosos de liberar a su líder, así como también se omite la captura y el encarcelamiento de Humberto Ortega (hermano de Daniel O.) y del costarricense Plutarco Hernández, entre otros. No se indica que los prisioneros, incluyendo a Carlos Fonseca Amador, son trasladados a la Penitenciaría Central ${ }^{10}$. En la novela, después de ese primer intento de escape, la trama continúa en la misma cárcel y sin señalar su ubicación.

Con respecto al canje exitoso de prisioneros, noticias de 1970 indican que se secuestró un avión de LACSA que había salido del aeropuerto de Limón y en el cual viajaban cuatro técnicos norteamericanos de la United Fruit Company ${ }^{11}$. El avión secuestrado aterrizó en San Andrés y, desde ahí, se exigió la liberación de los cuatro prisioneros (incluyendo la del costarricense). Gracias a la presión ejercida, liberaron a los 4 sandinistas quienes abordaron un avión que realizó escala en México, antes de su destino final: la Cuba revolucionaria castrista. En contraposición, la novela plantea que se secuestra un avión y que Fonseca sale del país en ese mismo avión y en compañía de la tripulación original, la cual habría participado gustosamente del plan para liberar al guerrillero (p. 182).
Como recuento de esta breve e incompleta comparación del registro histórico y el ficcional, el texto no incluye la muerte del policía costarricense, no da detalles del secuestro del avión de LACSA, no menciona la participación costarricense en los intentos de liberación, ni la presión de los EE.UU., así como tampoco ahonda en una representación más certera de cómo manejó Figueres la compleja situación política internacional. El objetivo de señalar estas omisiones no es determinar cuál es la verdad, pues no se trata de castigar a la novela por no plantearse un apego más riguroso a una verosimilitud histórica. Lo interesante es detenerse a pensar qué significan esas manipulaciones, pues como señala Magdalena Perkowska "la novela histórica contemporánea (...) busca distintas maneras de articular su problemática relación con lo real" (2006, p. 25).

En suma, gracias a estas simplificaciones, el texto se ahorra la embarazosa tarea de justificar las acciones violentas del comando sandinista como medios indispensables para alcanzar la meta final. Si intentara establecer la legitimidad de la lucha sandinista desde un punto de vista más comprometido con la recreación histórica de los eventos de 1969-1970, entonces perjudicaría la transparencia del mensaje por transmitir. En otras palabras, aumentaría el riesgo de ambigüedad interpretativa de la novela. Opta entonces por bajar la intensidad al conflicto internacional y descentrarlo con el fin de que la audiencia costarricense pueda comprender los motivos de la lucha desde su muy particular horizonte de expectativas.

En pocas palabras, la reconstrucción histórica somera de ambos planos temporales es la única vía para sostener esa relación alumnomaestro entre Ernesto, personaje literario y absolutamente ficticio y la representación de Carlos, como una persona totalmente accesible y relajada en circunstancias tan adversas. Como señalaba en la introducción, gracias a estas mediaciones que acercan al otro, se logra proyectar la solidaridad y combatir la indiferencia con respecto a la "lucha heroica del país vecino" (p. 147). De esa manera, se comprenden las 
palabras de Ernesto, quien después del primer intento de fuga señala:

El país entero admira al hombre que se atreve a oponerse al tirano y aunque no desean comprometerse en un apoyo colectivo, íntimamente se deben alegrar de su libertad. Los crímenes del tirano repercuten en nuestro país y todos despreciamos sus métodos y su crueldad. (p. 166).

\section{Conclusión}

Como reflexión final, quisiera destacar el mecanismo para provocar esa solidaridad. Se basa en la necesidad de reconocerse en el espejo de la otredad; sin embargo, ese afán de reconocimiento se lleva aún más lejos: ellos quieren ser como fuimos nosotros. En otras palabras, nuestra mismidad es un proyecto en sí al cual esta otredad aspira. Como nos reconocemos en ellos, los apoyamos. Para provocar ese acercamiento, son necesarias las mediaciones anteriormente descritas en cuanto a lo que se entiende por revolución. Es una solidaridad a la tica, construida a la medida de la audiencia nacional, basada en términos estereotípicamente muy costarricenses: neutra, orientada hacia la paz y la institucionalidad, es decir, concentrándose en los marcadores identitarios costarricenses.

Asimismo, el no abordar la hibridez genérica empobrece las interpretaciones de una novela que se nutre de la novela de tesis, de la experimentación y de la nueva novela histórica, entre otros. En este artículo, se subraya puntualmente el acercamiento de El eco de los pasos con respecto a la novela de tesis en el entendido de que "es un género que solo se puede entender vinculado con un metadiscurso con el que coincide históricamente en el momento de su aparición" (López, 1999, p. 5). Obviar, por ejemplo, dicho metadiscurso y el horizonte de expectativas de la audiencia costarricense impide trascender la paradoja de la doble utopía fallida, dado que ya sabemos que la revolución sandinista tampoco logró triunfar.

Finalmente, es importante profundizar una relectura a partir de las coordenadas de la literatura comprometida, revolucionaria, de la dramatización de lo inmediato, para usar la expresión de Samuel Rovinski al referirse a su drama El martirio del pastor (Rovinski \& Rokas, 1996, p. 221). Al perpetuar lecturas sobre El eco de los pasos centradas en la denuncia de la situación costarricense de finales de los años 70 , se pasa por alto que forma parte de los primeros textos no nicaragüenses en promover la solidaridad con la causa sandinista. Desde ese punto de vista, se revela como un texto muy particular de la literatura costarricense, generalmente considerada indiferente ante los movimientos revolucionarios contemporáneos.

\section{Notas}

1. Sobre El eco de los pasos, Álvaro Quesada Soto señala que retoma la denuncia social de la generación del 40 y que, al igual que otras novelas de la época, marca el contraste entre ideales patrióticos que guiaron al 48 y el nuevo orden construido Quesada Soto (2000, p. 71). Como vimos, Jacinto Brenes apoya esta lectura de denuncia de la Segunda República. Por su parte, como retomo después, el escritor Rodrigo Soto va más allá e indica que representa la versión oficial de los vencedores del 48 (2011, p. 39). Asimismo, David Díaz se refiere a la novela de Pinto pero únicamente considerándola como relectura del 48. En suma, solo se mencionan ocasionalmente el plano relativo al movimiento revolucionario nicaragüense y la idea de solidaridad.

2. Señala Suleiman que las novelas de tesis se escriben en modo realista con una intención didáctica orientada a demostrar la validez de una doctrina política, filosófica o religiosa (1993, p. 7)

3. La novela incluye la siguiente dedicatoria: "A la memoria de/ Carlos Fonseca Amador/ Amado Soler Fernández/ Efraín Arroyo Blanco" (p. 21).

4. Llama la atención la diferencia de edad entre los personajes, pues resulta evidente que Ernesto es mayor que Carlos. De esta forma se invierte la relación profesor-estudiante tradicional.

5. Indica Suleiman que la figura arquetípica del dador es la figura paternal. Posee un conocimiento similar, si no idéntico al que persigue el héroe. Es un padre espiritual. Desde ese punto de vista, un héroe 
respaldado por un dador/ayudante fuerte pasará las pruebas con el fin de lograr un aprendizaje positivo. Un héroe que no tenga ese modelo apoyo no será capaz de hacerlo y, como resultado, su aprendizaje será negativo (1993, pp. 80-84).

6. Al respecto de la participación de la Legión del Caribe en el conflicto civil costarricense, consultar Alemán (2013, p. 113)

7. Expresión de Russell Hardin, citada por SpinnerHalev Spinner-Halev (2008, p. 612).

8. Señala Steven Palmer que en 1969 Fonseca publica Nicaragua: hora cero. Allí, señala Palmer, se refiere a los primeros años del FSLN y al conflicto con respecto a la adhesión marxista-leninista y a Sandino como punto de origen (1988, pp. 95-99).

9. Consultar Díaz (13 mayo 2013).

10. Consultar Ministerio de Seguridad Pública (1970, pp. 2-3).

11. Consultar "Los secuestradores" (22 de octubre 2000).

\section{Bibliografía}

Alemán, C. E. (2013). Nicas belicosos: nicaragüenses en la guerra civil de Costa Rica, 1948. Anuario de Estudios Centroamericanos, (39), 111-141.

Brenes Molina, J. (2003). Tres novelas en busca de un juicio histórico. Revista Comunicación, $12(1-2), 50-63$.

Díaz,D. (13 mayo 2013). El 48 como ficción y como historia. Literofilia. Retrieved from http:// literofilia.com/?p=12073\&print=print

Fernández Utrera, María Soledad. (1996). Julio Cortázar y Libro de Manuel: pensamiento y narrativa en torno al concepto de "revolución". Revista Canadiense de Estudios Hispánicos, 20(2), 225-240. doi:10.2307/27763281
González-Echeverría, R. (2001). La voz de los maestros. Escritura y autoridad en la literatura latinoamericana moderna. Madrid: Verbum.

López, I. J. (1999). Revolución, Restauración y noveladetesis.RevistaHispánicaModerna, 52(1), 5-23. doi:10.2307/30203547

Los secuestradores (22 de octubre 2000). La Nación. Retrieved from http://wvw. nacion.com/dominical/2000/octubre/22/ secuestradores.html

Ministerio de Seguridad Pública. (1970). Sección N. Principales actividades desplegadas. In Ministerio de Seguridad Pública (Ed.), Memoria anual del Ministerio de Seguridad Pública 1969-1970 (pp. 2-3). San José.

Moylan, T. O. (1998). Introduction: Jameson and Utopia. Utopian Studies, 9(2), 1-7. doi:10.2307/20719757

Palmer, S. (1988). Carlos Fonseca and the Construction of Sandinismo in Nicaragua. Latin American Research Review, 23(1), 91-109. doi:10.2307/2503321

Perkowska, M. (2006). La novela histórica contemporánea entre la referencialidad y la textualidad: ¿una alternativa falaz en la crítica latinoamericana? Confluencia, 22(1), 16-27. doi:10.2307/27923177

Pinto, J. (1984). El eco de los pasos. San José: Editorial Costa Rica.

Quesada Soto, Á. (2000). Breve historia de la literatura costarricense. San José: Editorial Porvenir.

Rhoden, Laura H. Barbas. (1999). El papel del testimonio después de la victoria: Omar Cabezas y el discurso revolucionario en 
Nicaragua. Confluencia, 14(2), 63-75. doi:10.2307/27922690

Rodó, J. E. (1968). Ariel. In R. Lazo (Ed.), Ariel. Liberalismo Y Jacobinismo. Ensayos (pp. 1-59). Mexico: Editorial Porrúa.

Rovinski, S., \& Rokas, N. W. (1996). Samuel Rovinski y el teatro contemporáneo en Costa Rica. Confluencia, 11(2), 213-232. doi:10.2307/27922376

Solís, M. A. (2007-2008). El 48 como desborde trágico. Anuario de Estudios Centroamericanos, (33/34), 261-295.
Soto, R. (2011). Construcción y demolición del mito de la excepcionalidad: acercamiento a la literatura costarricense. Pórtico, (1), 27-44. Retrieved from https://issuu.com/ editorialcostarica/docs/portico21_numerol

Spinner-Halev, J. (2008). Democracy, Solidarity and Post-nationalism. Political Studies, 56(3), 604-628. doi:10.1111/j.14679248.2007.00708.x

Suleiman, S. R. (1993). Authoritarian Fictions: The Ideological Novel as a Literary Genre. Princeton: Princeton University Press.

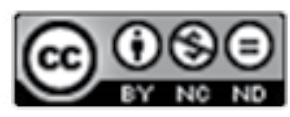

Este obra está bajo una licencia de Creative Commons Reconocimiento-NoComercial-SinObraDerivada 4.0 Internacional. 